\title{
Tiny but mighty: a rare case of os peroneum fracture
}

\author{
Mohammed Abrahim ${ }^{1}\left[\right.$ [ Neil Dilworth ${ }^{1}$
}

Received: 26 November 2020 / Accepted: 23 December 2020 / Published online: 15 January 2021

(C) The Author(s), under exclusive licence to Canadian Association of Emergency Physicians (CAEP)/ Association Canadienne de Médecine d'Urgence (ACMU) 2021

Keywords Os peroneum $\cdot$ Painful os peroneum syndrome $\cdot$ POPS $\cdot$ Foot pain $\cdot$ Accessory bones $\cdot$ Foot fractures $\cdot$ Missed fracture $\cdot$ Rare fracture

\section{Abbreviations \\ POPS Painful os peroneum syndrome \\ ED Emergency Department \\ EP Emergency Physician}

\section{Introduction}

The os peroneum is an accessory ovoid ossicle of the foot, embedded in the substance of the peroneus longus tendon and located lateral to the plantar aspect of the cuboid bone of the foot [1].

Os peroneum accessory ossicles may appear round or oval and are usually unilateral and bipartite, but they could be single and unilateral in approximately $30 \%$ of cases [2]. Fractures of the os peroneum are commonly overlooked on plain radiographs due to their subtlety and the difficulty to differentiate fractures from the normal common variant of the bipartite os peroneum. Missed os peroneum fracture could lead to significant functional disability.

On plain radiographs, os peroneum fractures are better identified via an oblique view of the foot. Both, plain radiography and computed tomography (CT), may demonstrate displacement of the os peroneum from its usual position, fracture, or diastasis of a bipartite sesamoid [2]. Proximal displacement of the os peroneum is an indirect sign of a peroneal tendon rupture [2]. The mechanism of acute fractures of the os peroneum occurs with sudden inversion of the ankle resulting in fracture and possible disruption of the peroneus longus tendon.

Mohammed Abrahim

mabrahim@haltonhealthcare.com

1 Department of Emergency Medicine, Georgetown Hospital, Halton Healthcare, 1 Princess Anne Drive, Georgetown, ON L7G 2B8, Canada
Treatment options for fracture of the os peroneum vary and there is no consensus as to the best approach. However, it is acceptable to treat non-displaced fractures conservatively with immobilization and analgesia followed by physiotherapy [3]. Early operative intervention should be considered in those who require an immediate return to physical activity (for example, high-level/professional athletes) [3].

If left untreated, os peroneum fracture and the resultant peroneal ligament disruption may be complicated by painful os peroneum syndrome (POPS) which is a chronic pain condition presenting as lateral midfoot pain. POPS is closely linked to the healing process of a fracture, with possible rupture of the peroneus longus tendon or chronic diastasis of the os peroneum, with a variable frequency of tendonitis or tenosynovitis of the peroneus longus tendon leading to eversion weakness [4].

\section{Presentation}

A 50-year-old male presented to a community Emergency Department (ED) with subacute right foot pain for 2 weeks. His condition started following an inversion injury of the right foot. He was seen the same day of the injury at a walkin clinic and received a plain radiograph of the foot which was interpreted as normal and was diagnosed as foot sprain. As a result; he was prescribed analgesia and physical rest, no follow-up was arranged. His pain and the swelling did not resolve; he continued to limp on that foot and proceeded to visit the hospital for further analgesia.

Upon examination, he had a limping gait and right foot examination revealed localized tenderness and swelling over the lateral aspect of the foot with the point of maximal tenderness proximal to the base of the 5th metatarsal. The rest of the examination was unremarkable.

Repeat plain radiographs of the right foot revealed a fracture of one of the cuboid bones on the lateral view 


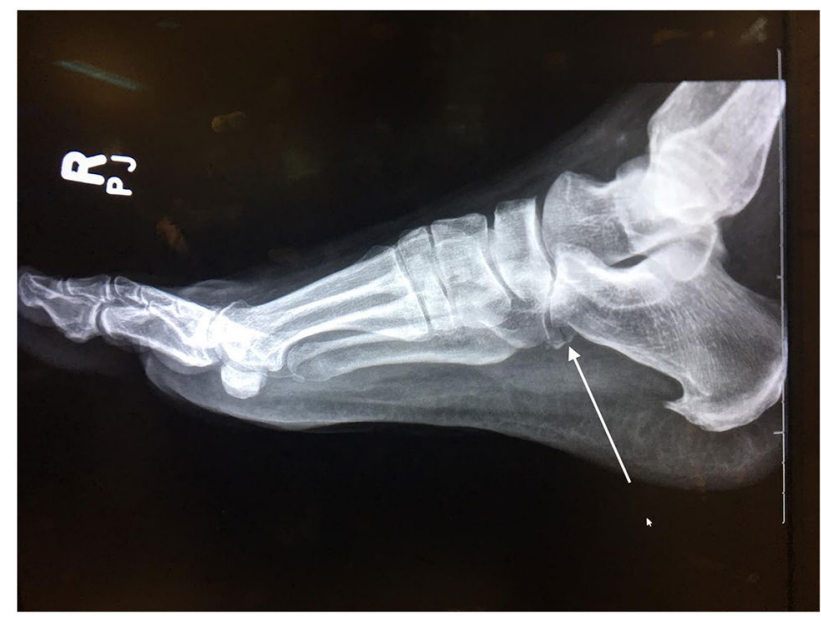

Fig. 1 Lateral view demonstrating unidentified fracture of os peroneum

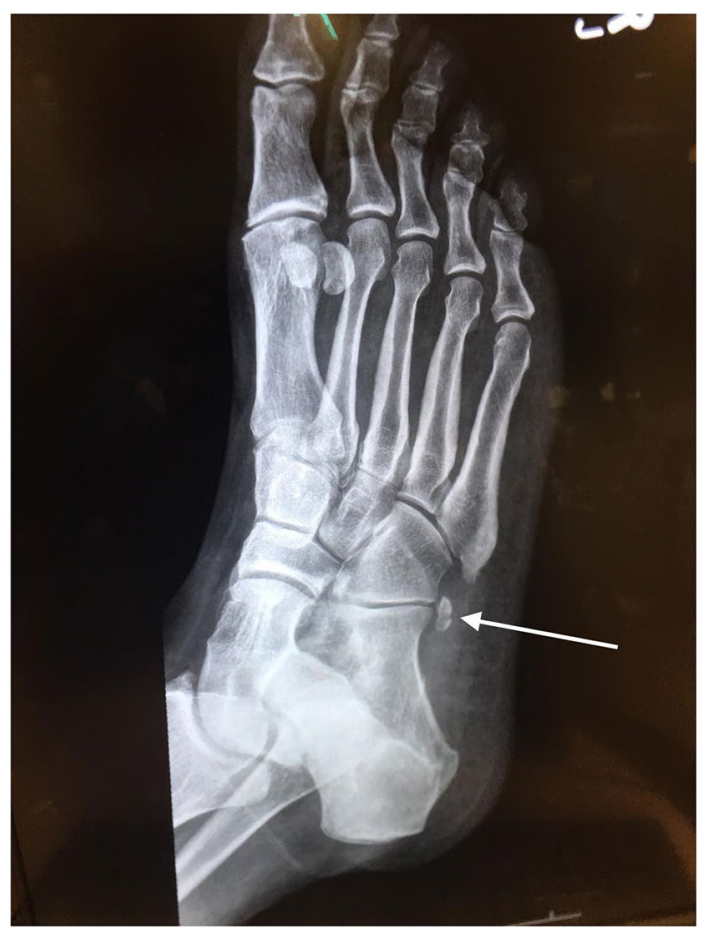

Fig. 2 Oblique view of the right foot demonstrating a horizontal fracture through the middle of os peroneum

(Fig. 1). However, on the oblique view (Fig. 2), it became evident that the fracture was of the body of the os peroneum. We later reviewed the patient's initial radiographs and found that the fracture was apparent but was missed. We immobilized his foot and referred him for an orthopedic surgery consultation for possible surgical intervention because his job required daily prolonged walking.

\section{Impression}

We report a case of a 50-year-old male who presented to a walk-in clinic with a subacute right foot injury. The os peroneum fracture was initially missed which caused the patient acute dysfunction, including an inability to work, requiring him to visit our Emergency Department where we diagnosed the rare fracture.

We report this case in part to emphasize the importance of being vigilant for such a potentially disabling, yet rare, injury and also as a teaching tool for physicians of different disciplines such Family, Emergency, Sports Medicine, Diagnostic Radiology, and Orthopedic surgery (in addition to Physiotherapy and Rehabilitation) who are dealing with minor foot trauma.

It is crucial to differentiate between the normal variant of bipartite ossicle and fractured single os peroneum because Emergency physicians are usually the first to interpret plain radiographs at Emergency Departments before receiving the formal radiologist reports. Within these settings, the patient often departs before the radiologist interpretation report becomes available [5].

\section{Conclusion}

Os peroneum fracture is rare, but when overlooked it could carry a great deal of functional disability manifested as the painful os peroneum syndrome (POPS). Physicians should consider the diagnosis of fractured os peroneum even in the event of normal radiographs which begets repeating the plain radiographs or requesting advanced imaging such as ultrasound, CT scan, or MRI if pain persists. Early operative repair is recommended for competitive athletes and when prolonged standing or walking is part of a patient's daily job and activities.

Funding None.

\section{Compliance with ethical standards}

Conflict of interest The authors declare that they have no conflict of interest.

Informed consent Written informed consent was obtained to use in the clinical case presentation including the use of the patient's plain radiographs. 


\section{References}

1. Nwawka OK, Hayashi D, Diaz LE, Goud AR, Arndt WF, Roemer FW, Malguria N, Guermazi A. Sesamoids and accessory ossicles of the foot: anatomical variability and related pathology. Insights Imaging. 2013;4(5):581-93.

2. Sobel M, Pavlov H, Geppert MJ, Thompson FM, DiCarlo EF, Davis WH. Painful os peroneum syndrome: a spectrum of conditions responsible for plantar lateral foot pain. Foot Ankle Int. 1994;15(3):112-24.
3. Heckman DS, Reddy S, Pedowitz D, Wapner KL, Parekh SG. Operative treatment for peroneal tendon disorders. JBJS. 2008;90(2):404-18.

4. Chagas-Neto FA, Souza BN, Nogueira-Barbosa MH. Painful os peroneum syndrome: underdiagnosed condition in the lateral midfoot pain. Case Rep Radiol. 2016;1:2016.

5. Torreggiani WC, Nicolaou S, Lyburn ID, Harris AC, Buckley AR. Emergency radiology in Canada: a national survey. Can Assoc Radiol J. 2002;53(3):160. 